\title{
Hyperprolactinemia in Systemic Lupus Erythematosus
}

\author{
Menaka Shanthi Kandasamy $^{1 *}$, K. Pramila ${ }^{1}$ and M. Divya ${ }^{2}$ \\ ${ }^{1}$ Department of Biochemistry, ICH \& HC, MMC, Egmore, Chennai- 600008, Tamil Nadu, India \\ ${ }^{2}$ Department of Biochemistry, Government Omandurar Multispeciality Hospital, \\ Chennai, Tamil Nadu, India \\ *Corresponding author
}

A B S T R A C T

Keywords

Prolactin,

Cytokine,

Autoimmune

disorders,

Pathophysiological

role, Systemic

Lupus

Erythematosus.

Article Info

Accepted:

26 April 2017

Available Online:

10 May 2017
Prolactin, the protein hormone synthesized and secreted predominantly by anterior pituitary gland plays major role in galactopoeisis. The secretion of prolactin is not confined to pituitary alone; there are many immune cells in our body that mediate secretion of prolactin. The prolactin secreted by these immune cells functions as a cytokine that mediate proliferation and maturation of $\mathrm{T}$ and B Lymphocytes. Thus prolactin is a dual function protein, as a hormone and as a cytokine. The effect of prolactin over proliferation of $\mathrm{T}$ cells has unleashed the possible pathophysiological role of prolactin in several autoimmune disorders. In the present study we compared the level of prolactin in lupus patients with healthy controls. Prolactin levels were significantly elevated in lupus patients compared to healthy controls $(\mathrm{P}<0.05)$. This proves the possible pathophysiological role of prolactin in systemic lupus erythematosus. Hence utilization of prolactin antagonists can have significant role in therapy of systemic lupus erythematosus as well as in preventing the complications associated with systemic lupus erythematosus.

\section{Introduction}

Prolactin is a dual function protein that functions both as a hormone as well as a cytokine (Ben-Jonathan et al., 1996). Prolactin is synthesized and secreted from pituitary gland and its primary role is to help initiate and maintain breast milk production in pregnant and nursing women (PRL prolactin). Prolactin is also synthesized and secreted from the cells of the immune system such as macrophages, natural killer cells, and T- and B-lymphocytes. Prolactin secreted from the immune cells act by stimulating the secretion of other cytokines as well asfunctions as a survival and growth and factor. The gene for prolactin is located in chromosome 6 , the genetic locus is $6 \mathrm{p} 22.32$. The prolactin gene is nearly $10 \mathrm{~Kb}$ in size and the gene has 5 exons and 4 introns (Cooke et al., 1981). Mature human prolactin has 199 aminoacids and has molecular mass of approximately 23,000 Daltons. Prolactin on binding to its target prolactin receptor results in the activation JAK-STAT pathway. This augments the intracellular expression of IRF1 (Interferon regulatory factor 1) that cause transcription of IFN- $\gamma$ which mediates the 
maturation of T and B cells (Yu-Lee, 2001). The assessment of serum prolactin will be useful in clinical conditions like: Galactorrhea, menstrual irregularities and/or infertility in women, infertility and erectile dysfunction in men, prolactinomas- to monitor the treatment and to detect recurrences, evaluation of anterior pituitary function.

Recent clinical and experimental studies support the potential role of prolactin (PRL) as a promoter of clinical activity and severity of Systemic lupus erythematosus (SLE). SLE is the autoimmune condition more common among young women of reproductive age. The distribution of hyperprolactinemia among healthy adults is $0.4 \%$ (Biller et al., 1999; Miyai et al., 1986). But the distribution of hyperprolactinemia among SLE population is 15-33\% (Leanos-miranda et al., 2006; Buskila et al., 1996).

Autoimmune disorders have general preponderance for female population. The activity of these autoimmune disorders gets worsened during pregnancy and post-partum. These above observations have led to the hypothesis that elevated prolactin and estrogen plays crucial role in pathogenesis of autoimmune disorders. Besides peeve et al., in 2005 have proved the classic role of prolactin in immunomodulation (Peeva et al., 2005; 2003). Russel et al., (1985) have also proved the expression of prolactin receptors in human $\mathrm{T}$ and $\mathrm{B}$ lymphocytes.

Even though the pathogenic role of prolactin in SLE has been well established, and SLE is a common disorder among Asian population, the studies establishing the role of prolactin in SLE are limited and the results are contradictory. This study is done to assess the prolactin status among the lupus population and also assess the degree of hyperprolactinemia with lupus associated complications. The aim of the current study is to establish the role of prolactin in systemic lupus erythematosus and also to assess the degree of hyperprolactinemia in lupus individuals.

\section{Materials and Methods}

\section{Study population}

\section{Cases}

50 proven lupus patients attending lupus clinic (Rheumatology OPD) were included as cases.

\section{Controls}

50 age and sex matched healthy controls were included and compared with the cases.

Pregnant or lactating women and those with known pathological conditions affecting the prolactin status (eg: prolactinoma, primary hypothyroidism or any drugs affecting the prolactin status) were excluded from the study.

\section{Sample fasting serum sample}

Whole blood was collected in plain (red top) tubes from cases and controls. Serum was separated immediately and stored at $-20^{\circ} \mathrm{C}$. Only Fasting samples were collected, as grossly lipemic samples interfere with the assay of prolactin.

Samples were analyzed for: Blood Urea by GLDH method, Serum Creatinine by modified Jaffes method, Serum Uric acid by enzymatic method.

All analytes were measured using a semiautomated analyser.

Prolactin was assayed by standard sandwich ELISA methodology. The normal range of 
serum prolactin is $3-25 \mathrm{ng} / \mathrm{mL}$ for healthy adults.

\section{Results and Discussion}

Prolactin, the pituitary hormone involved in lactation can also function as a cytokine involved in immune response. The cells that secrete prolactin exhibit receptor for prolactin. Prolactin in the micro-environment contributes to the differentiation and maturation of immune cells.

The prolactin on the target cells activates predominantly the JAK/STAT pathway as well as the Ras/Raf/MAPK pathway. The receptors for prolactin action are the members of the Class I hematopoietin/cytokine receptor family $^{12}$. The cells of the immune system that express prolactin receptors include spleen cells, thymus cells, bone marrow cells, lymphocytes, and monocytes12. The constitutive expression of prolactin receptors on the resting T-cells 13 indicates the key role of prolactin in immune system. Structural analysis of prolactin and its receptors have revealed the relationship of prolactin to the cytokine family. The role of prolactin as a cytokine was well established by several investigatory studies, that explains the detailed physiologic role of prolactin as a cytokine. The level of this immune cells derived cytokine was regulated by other cytokines like IL-2, IL-1 $\beta$ \& IL-4. The major pro-inflammatory cytokine, TNF- $\alpha$ stimulates the secretion of prolactin from $\mathrm{T} \& \mathrm{~B}$ cells (Stevens et al., 2001; Hatfill et al., 1990). The above studies well established the cytokine role of prolactin.

Mendez et al., in 2004 have reported that increased secretion of prolactin in SLE18. Since then many case control studies have established the role of prolactin in SLE (Larrea et al., 1997; Aringeret al., 2004; Jara et al., 1992). Smiti et al., in 2004 have reported that eventhough prolactin levels were elevated in all SLE patients the elevation is not statistically significant (SmitiKhanfir et al., 2004).

Table.1 The level of prolactin in plasma

\begin{tabular}{|c|c|c|c|}
\hline ANALYTE & CASES & CONTROLS & p-Value \\
\hline Prolactin & $51.6 \pm 20.8$ & $13.2 \pm 5.2$ & $<0.05(\mathrm{p}=0.048)$ \\
\hline Age in years & $28.1+8.43$ & $29.1+9.03$ & Not significant \\
\hline Urea & $51.9 \pm 16.9$ & $18.2 \pm 7.0$ & $<0.05(\mathrm{p}=0.048)$ \\
\hline Creatinine & $2.1 \pm 0.69$ & $0.8 \pm 0.3$ & $<0.05(\mathrm{p}=0.046)$ \\
\hline Uric acid & $11.4 \pm 3.1$ & $3.5 \pm 1.8$ & $<0.05(\mathrm{p}=0.041)$ \\
\hline
\end{tabular}

The level of prolactin in plasma was compared between cases and controls by unpaired t test. There is significantly higher level of prolactin among cases compared to that of control population ( $\mathrm{P}$ value $<0.05$ ) 
Mok et al., in 1998 has reported "hyperprolactinemia occurred in a small proportion of male patients with SLE but its significance remained unclear. Serum PRL level did not correlate with disease activity and was not a reliable marker for disease monitoring". The studies establishing the role of prolactin in SLE have given disputing results and the Indian studies establishing the role are limited. In our study we assayed the levels of prolactin among cases and controls and found significantly elevated level of prolactin in SLE patients compared to controls. PRL level was higher in patients with active disease than in patients with non-active disease.

It is concluded that the Prolactin, as a hormone and as a cytokine is necessary for the maintenance of homeostasis of the organism.PRL as a cytokine presents some defined functions in immunomodulation, especially in relation to Th1 response.

Prolactin in immune system is responsible for the survival of the organism as it promotes the proliferation of $\mathrm{T}$ and $\mathrm{B}$ cells. The hormone in normal levels is responsible for the immune tolerance whereas excess prolactin would break the immune tolerance leading to autoimmune disease or worsening of existing autoimmune disorder.

The current study clearly demonstrates the elevation of serum prolactin in serum of lupus individuals. It requires further research to determine whether elevated prolactin is the cause or effect of the SLE. Although in current situation, prolactin assay in lupus patients is not done on a routine basis, the assay is definitely required in lupus patients, or at least in cases associated with infertility and menstrual irregularities.

\section{References}

Aringer, M., J.S. Smolen. 2004. Tumour necrosis factor and other proinflammatory cytokines in systemic lupus erythematosus: a rationale for therapeutic intervention. Lupus, 133(4):43-47.

Ben-Jonathan, N., Mershon, J.L., Allen, D.L., Steinmetz, R.W. 1996. Extrapituitary Prolactin: Distribution, Regulation, Functions, and Clinical Aspects. Endocrine Rev., 17: 639-69.

Biller, B.M., A. Luciano, P.G. Crosignani, M. Molitch, D. Olive, R. Rebar, et al. 1999. Guidelines for the diagnosis and treatment of hyperprolactinemia. J. Reprod. Med., 44(12 Suppl): 1075-84.

Bole-feysot, C., V. Goffin, M. Edery, N. Binart, P.A. Kelly, 1998.P rolactin (PRL) and its receptor: actions, signal transduction pathways and phenotypes observed in PRL receptor knockout mice. Endocr. Rev., 192(2): 52-68.

Buskila, D., M. Lorber, L. Neumann, D. Flusser, Y. Shoenfeld. 1996. No correlation between prolactin levels and clinical activity in patients with systemic lupus erythematosus. J. Rheumatol., 23: 629-632.

Cooke, N.E., Coit, D., Shine, J., Baxter, J.D., Martial, J.A. 1981. Human prolactin cDNA structural analysis and evolutionary comparisons. J. Biol. Chem., 256: 40074016.

Gerlo, S., P. Verdood, E.L. Hooghe-peters, R. Kooijman. 2005. Modulation of prolactin expression in human $\mathrm{T}$ lymphocytes by cytokines, J. Neuroimmunol., 162(1-2): 190-3.

Hatfill, S.J., R Kirby, M Hanley, E Rybicki, L Bohm, 1990. Hyperprolactinemia in acute myeloid leukemia and indication of ectopic expression of human prolactin in blast cells of a patient of subtype M4. Leuk Res., 14(1): 57-62.

Jara, L.J., C. Gomez-sanchez, L.H. Silveira, P. Martinez-osuna, F.B. Vasey, L.R. Espinoza. 1992. Hyperprolactinemia in systemic lupus erythematosus: association with disease activity. Am. J. Med. Sci., 303(4): 222-6.

Larrea, F., A. Martinez-castillo, V. Cabrera, J. Alcocer-varela, G. Queipo, C. Carino, et al. 1997. A bioactive 60-kilodalton prolactin species is preferentially secreted in cultures 
of mitogen-stimulated and nonstimulated peripheral blood mononuclear cells from subjects with systemic lupus erythematosus. J. Clin. Endocrinol. Metab. http://dx.doi.org/10.1210/jcem.82.11.4356

Leanos-miranda, A., G. Cardenas-mondragon. 2006. Serum free prolactin concentrations in patients with systemic lupus erythematosus are associated with lupus activity, Rheumatol. Oxford, 4(5): 97-101.

Mendez, I., Carino, C., Diaz, L. Prolactin in the immunological system: synthesis and biological effects. Rev. Invest. Clin., 57(3): 447-56.

Mendez, I., J. Alcocer-varela, A. Parra, a Lavazavala, D.A. De La Cruz, D. Alarconsegovia. et al. 2004. Neuroendocrine dopaminergic regulation of prolactin release in systemic lupus erythematosus: a possible role of lymphocyte-derived prolactin. Lupus, 13: 453.

Miyai, K., K. Ichihara, K. Kondo, S. Mori. 1986. Asymptomatic hyperprolactinaemia and prolactinoma in the general population-mass screening by paired assays of serum prolactin. Clin. Endocrinol., (Oxf) 25(5): 549-54.

Mok, C.C., Lau, C.S., Lee, K.W., Wong, R.W. 1998. Hyperprolactinemia in males with systemic lupus erythematosus. $J$. Rheumatol., 25(12): 2357-63.

Peeva, E., Michael, D., Cleary, J., Rice, J., Chen, X., Diamond, B. 2003. Prolactin modulates the naïve B cell repertoire. $J$. Clin. Invest., 111: 275-83.

Peeva, E., Zouali, M. 2005. Spotlight on the role of hormone factors in the emergence of autoreactive B-lymphocytes. Immunol. Lett., 101:123-43.

Pellegrini, I., J.J Lebrun, S. Ali, P.A. Kelly. 1992. Expression of prolactin and its receptor in human lymphoid cells. Mol. Endocrinol., 610(23): 10-31.

PRL

prolactin [(human)]www.ncbi.nlm.nih.gov/gene/5617

Russell, D.H., Kibler, R., Matrisian, L., Larson, D.F., Poulos, B., Magun, B.E. 1985. Prolactin receptors on human $\mathrm{T}$ and $\mathrm{B}$ lymphocytes: antagonism ofprolactin binding by cyclosporin. J. Immunol., 134: 3027-3031.

Smiti Khanfir, M., Ben Ghorbel, I., Feki, M., Lamloum, M., Mebazaa, A., Miled, M., Houman, M.H. 2004. Hyperprolactinemia in systemic lupus erythematosus. A prospective study of 38 cases: Tunis Med., 82(6): 512-5.

Stevens, A., D. W. Ray, J. Worthington, J.R. Davis. 2001. Polymorphisms of the human prolactin gene--implications for production of lymphocyte prolactin and systemic lupus erythematosus. Lupus, 10(10): 676-83.

Yu-Lee, L.2001. Stimulation of interferon regulatory factor-1 by prolactin. Lupus, 10(10): 691-9.

\section{How to cite this article:}

Menaka Shanthi Kandasamy, K. Pramila and Divya, M. 2017. Hyperprolactinemia in Systemic Lupus Erythematosus. Int.J.Curr.Microbiol.App.Sci. 6(5): 2788-2792. doi: https://doi.org/10.20546/ijcmas.2017.605.313 